Gestão e Desenvolvimento, 22 (2014), 269-289

\title{
INFLUÊNCIA DO CUIDADOR INFORMAL NA REABILITAÇÃO DO DOENTE, NO CONTEXTO DOS CUIDADOS CONTINUADOS ${ }^{1}$
}

\author{
Vanessa Figueiredo ${ }^{2}$ \\ Maria Olivia Dias ${ }^{3}$ \\ Alexandre Oliveira ${ }^{4}$
}

\begin{abstract}
Resumo: Perceber de que modo a presença dos Cuidadores Informais afeta positiva ou negativamente a reabilitação dos doentes, no contexto dos Cuidados Continuados, foi o objetivo central deste estudo.

A Unidade de Cuidados Continuados de Longa Duração $e$ Manutenção pertencente à Santa Casa da Misericórdia de Mangualde, onde foi realizado o presente estudo, integra doentes em situação de dependência, na sua maioria idosos. A dependência de idosos acarreta para os cuidadores sobrecarga, pelos cuidados físicos, psicológicos e socias que têm a prestar ao idoso dependente. Cuidar implica sentimentos de afeto, informação acerca dos cuidados necessários e ter em consideração fatores inerentes ao cuidador. Este emerge principalmente no seio familiar, sendo o conjugue ou filhos os cuidadores mais comuns.

Lidar com a doença e dependência tem implicações tanto para o doente como para os familiares, nomeadamente psicológicas, com a adaptação à nova situação de vida. Se a aceitação/compreensão por parte das pessoas que rodeiam o doente for positiva, o próprio doente irá sentir-se apoiado e também adaptar-se melhor à sua condição de vida. Integrar o cuidador informal no processo de reabilitação do doente, constitui uma mecanismo de motivação para o próprio doente,
\end{abstract}

\footnotetext{
${ }^{1}$ Este artigo é, parcialmente, parte integrante do relatório de Estágio de Licenciatura em Serviço Social, apresentada no Pólo de Viseu da Universidade Católica Portuguesa, em 2013.

2 Técnica Superior de Serviço Social na Beirodial - Centro Médico e Diálise de Mangualde e Mestranda em Serviço Social, Pólo de Viseu da Universidade Católica Portuguesa. E-mail: vanessa.fd.figueiredo@gmail.com

${ }^{3}$ Professora Auxiliar do Departamento de Economia, Gestão e Ciências Sociais do Pólo de Viseu da Universidade Católica Portuguesa. E-mail: profaoliviadias@gmail.com

${ }^{4}$ Diretor Técnico/Assistente Social da Unidade de Cuidados Continuados Integrados da Santa Casa da Misericórdia de Mangualde, Mestre em Recursos Humanos.
} 
provocando neste sentimento de conforto e apoio das pessoas que lhe são queridas.

Para concretização deste estudo, realizaram-se trinte e três inquéritos por questionário aplicado através do contato direto aos Cuidadores Informais da Unidade de Cuidados Continuados da Santa Casa da Misericórdia de Mangualde.

Das conclusões retiradas deste estudo, e em termos genéricos, podese dizer que o Cuidador Informal influência positivamente a reabilitação dos doentes, caso estes se sintam bem com a sua presença.

Palavras-chave: Cuidador Informal; Reabilitação; Cuidados Continuados; Família; Idosos; Dependência.

\title{
INFLUENCE OF INFORMAL CAREGIVER IN REHABILITATION OF THE PATIENT, IN THE CONTEXT OF CARE CONTINUUM
}

\begin{abstract}
The goal of this study was to understand how the presence of Informal Caregivers affect positively or negatively the rehabilitation of the patients.

The Unity of Continuous Care in Long-Term care service and Maintenance belongs to Santa Casa da Misericórdia of Mangualde, place where this study was conducted, and it holds dependent patients, mostly elders. The elders dependence brings an overcharge to the caregivers due to physical, psychological and social care that they have to give them. Take care implies affection, treatment knowledge and awareness of caretaker limits. This person emerges mainly from family environment, being the spouse or sun the most common caregivers.

Dealing with the disease and dependence has implications both for patient and family, primarily psychological, as they adapt to the new way of living. If all those around the patient accept and understand positively the situation, the patient himself will feel supported and will adapt better to his new way of life. Taking the caretaker into the rehabilitation process brings additional motivation to the patient and creates a feeling of support and comfort from his dear ones.

For this study, thirty-three inquiries were realised in direct contact with the Informal Caregivers from the Unity of Continuous Care in Long-Term care service and Maintenance of Santa Casa da Misericórdia of Mangualde.

From this study, in generic terms, we can say that the Informal Caretaker influence positively the patients rehabilitation only if they're ok with their presence.
\end{abstract}

Keywords: Informal Caregivers; Rehabilitation; Continuous Care; Family; Elders; Dependence 


\section{INTRODUÇÃO}

Este estudo enquadra-se numa abordagem descritiva do reconhecimento das responsabilidades dos Cuidadores Informais, como elementos importantes no processo de acolhimento e reabilitação dos doentes, bem como parceiros de intervenção dos profissionais de saúde. "O papel do cuidador tem sido reconhecido como central numa abordagem multidisciplinar, na qual interagem diferentes profissionais" (Melo, 2005, citado por Pereira, 2011, p. 64). Verifica-se que o cuidador exerce influência na evolução das doenças principalmente na frequência e gravidade dos problemas comportamentais e na deterioração das capacidades funcionais

Porque sentiu-se, no terreno, que o convívio dos doentes com o Cuidador Informal é um fator positivo e favorecia a motivação destes para a sua reabilitação, decidiu-se realizar este trabalho de investigação. Assim constitui objetivo deste estudo, perceber de que modo a presença dos Cuidadores Informais afeta positiva ou negativamente a reabilitação dos doentes.

Com a participação da família nos cuidados de saúde, Cunha (2003, p. 62, citado por Monteiro, 2010, p. 51) verificou dois aspetos muito importantes: por um lado o doente sente uma maior ligação com o seu ambiente natural e familiar; por outro lado a família tem maior acesso à informação do que se passa com o doente, das intervenções realizadas e da evolução do doente e pode continuar a cuidar dele como se não estivesse internado, o que contribui para diminuir a ansiedade e o stress do prestador de cuidados.

Cuidadores Informais são pessoas que se responsabilizam pela assistência de outras pessoas, promovendo a sua qualidade de vida e satisfazendo as suas necessidades de vida diárias, sem formação profissional prévia, tendo como parceiros atualmente cuidadores formais, como Assistentes Sociais, Médicos, Enfermeiros, entre outros, como se verifica na Unidade de Cuidados Continuados. "Hoje o papel do cuidador tornou-se mais claro e imprescindível, no evoluir de uma sociedade que se quer mais humanizada na prestação integral de cuidados de saúde, que contribui conjuntamente com outros prestadores de cuidados de saúde para o bem-estar físico, psicológico e emocional do doente" (Unidade de Missão para os Cuidados Continuados, 2010, p. 30). 


\section{REVISÃO DA LITERATURA}

\subsection{O Idoso Dependente}

O envelhecimento demográfico é uma realidade patente em Portugal, sendo este um processo que varia de individuo para individuo consoante os fatores biológicos, psicológicos, ambientais, sociais, culturais, comportamentais, económicos, o género influenciam esse processo.

A probabilidade de adoecer aumenta com a idade cronológica, havendo maior ou menor vulnerabilidade do idoso a diversos fatores, como o meio onde está inserido, ou fatores que o tornam mais sensível como doenças, incapacidade e até dependência.

Dependência é "a situação em que se encontra a pessoa que, por falta ou perda de autonomia física, psíquica ou intelectual, resultante ou agravada por doença crónica, demência orgânica, sequelas póstraumáticas, deficiência, doença severa e ou incurável em fase avançada, ausência ou escassez de apoio familiar ou de outra natureza, não consegue, por si só, realizar as actividades da vida diária" (Decreto-Lei ${ }^{\circ} 101$, 2006, Art. $\left.{ }^{\circ} 3^{\circ} \mathrm{h}\right)$.

Azeredo (2011, p. 109) concorda dizendo que a dependência diz respeito à perda de autonomia, a não conseguir satisfazer as suas necessidades nem as Atividades de Vida Diárias (AVD's), sem ajuda de outrem.

A dependência deve-se principalmente à incapacidade física, mas também às dificuldades familiares, escassez de apoios sociais, isolamento, solidão, redução das capacidades psicológicas, recursos económicos escassos, entre outros.

A dependência pode ser total ou parcial, temporária ou permanente, podendo a gravidade desta variar com a aceitação ou não do individuo da doença. Um individuo pode ser dependente em determinados aspetos, como fisicamente ou a nível de afetividade e independente noutros aspetos, como financeiramente ou cognitivamente. As doenças crónicas são um exemplo dos efeitos diretos na capacidade dos indivíduos para satisfazer as suas AVD's e manter condições de vida independente (José, Wall \& Correia, 2002, p. 11).

A intensidade dos cuidados variam de acordo com o grau de dependência do individuo. Podem acontecer duas situações opostas, um individuo precisar de vigilância para realizar as suas AVD's ou então pode já não ter capacidade para, independentemente, realizar essas AVD's. Estas duas situações refletem diferentes níveis de incapacidade e grande variedade de situações. 
A dependência pode classificar-se em três graus: baixa dependência, em que os indivíduos necessitam apenas de supervisão nas AVD's; media dependência, em que além da supervisão necessitam da ajuda de terceiros para a realização de algumas atividades, como tomar banho, controlar a toma de medicamentos, entre outros; por fim elevada dependência, que significa que os indivíduos precisam de ajuda permanente e diária, não tendo capacidade para satisfazer as suas AVD's, como pessoas que se encontram acamadas ou deficit cognitivo (José, Wall \& Correia, 2002, p. 12).

O aumento da taxa de dependência de idosos traz efeitos à população ativa e cuidadora, como sobrecarga pelas despesas com pensões, cuidados de saúde e de suporte social (Azeredo, 2011, p. 24).

A satisfação das necessidades está inerente ao individuo desde a sua nascença. Na primeira etapa da vida esta é concretizada com a ajuda de terceiros, o mesmo volta a acontecer na última etapa da vida, devendo-se promover sempre a autonomia, a confiança, a autovalorizarão e a Qualidade de Vida (QDV) dos idosos.

Correa (1996, citado por Azeredo, 2011, p. 103) diz que quanto mais ativo tiver sido o idoso durante a sua vida, mais dinâmico tenderá a ser numa idade mais avançada, participando na vida social e envelhecendo de forma saudável, retardando a dependência

As Unidades de Cuidados Continuados não se destinam unicamente à população idosa, mas sim a todas as pessoas que estão em situação de dependência e que precisem de cuidados especializados para reabilitação e não seja necessário o internamento hospitalar, mas que no domicílio a prestação desses cuidados e reabilitação não seja possível.

\subsection{Família como Prestadora de Cuidados Informais}

A perda de autonomia, mesmo sem existência de doença, suscita ajuda de terceiros para satisfação das necessidades básicas, podendo essa ser do conjugue, pelo conhecimento e afetividade que detêm um do outro, outro familiar ou pessoas geograficamente próximas. Os cuidadores podem surgir pela perda progressiva da autonomia dos ascendentes ou na sequência de um acontecimento inesperado.

Cuidar, diz respeito a um ato individual ou a prestação de apoio a outrem nas suas necessidades. Cuidar de uma pessoa idosa no seio familiar, implica, para além do descrito, sentimentos de afeto, estar informado sobre o tipo e grau de dependência e ter em consideração 
fatores referentes ao cuidador (idade, disponibilidade, conhecimentos, entre outros) (Imaginário, 2004, p. 77).

O cuidador informal é um indivíduo, normalmente familiar, que segundo Imaginário $(2004$, p. 76$)$ "surge porque já existem previamente laços afetivos, daí o desejo de o idoso ser cuidado no domicílio". Porém também pode ser um "amigo ou vizinho que cuida, e é aceite como cuidador, de um doente não autónomo nas suas actividades de vida, prestando cuidados contínuos e constantes gratuitamente, baseado numa relação de afecto e/ou solidariedade, de responsabilidade e de dever, sem formação profissional em saúde. É responsável pelos trabalhos domésticos e tratamento das roupas, pela confecção das refeições, pela satisfação das AVD's afectadas e pelo apoio financeiro e psicológico" (Castro, 2008, p. 47).

Cuidar de doentes com patologia requer um maior esforço e envolvimento afetivo cada vez maior. Quando existe comunicação, harmonia e afetividade o cuidar pode resultar bastante bem, noutras situações pode causar alterações na estrutura familiar. Quando a família não consegue responder às necessidades do doente deve pedir ajuda externa (Azeredo, 2011, pp. 91-92).

Cuidar de um pessoa dependente ao fim de algum tempo acarreta tensões e stress devido aos aumento das responsabilidades, à sobrecarga económica, ao cansaço físico e emocional, à adequação das rotinas e das relações sociais do cuidador. A par desta sobrecarga, o cuidador informal, tem que ter capacidade emocional para lidar com a dependência do seu entre querido, acrescentando o fato de por vezes esse cuidador também ter problemas de saúde, ou serem agravados com o ato de cuidar.

No entanto, segundo Guerreiro (2009, p. 92) este tipo de cuidados informais é bastante utilizado por falta de recursos económicos mas também pelo aumento das pessoas com necessidade de ajuda, que acontecem devido às restrições dos sistemas assistenciais.

\subsection{Influência do Cuidador Informal na Reabilitação do Doente}

"A capacidade que os elementos, saudáveis, têm para lidar com a doença do seu familiar pode ter repercussões na saúde e funcionamento da família, bem como na adaptação física e psicológica do doente à situação" (Guerreiro, 2009, p. 92).

O seguinte quadro descreve o Processo de Trajetória da Doença nos Cuidadores Informais/Familiares (Adaptado de Enelow e col., 1999, citado por Monteiro, 2010, p. 44): 


\section{Quadro I}

Processo de Trajetória da Doença

\begin{tabular}{|c|c|c|c|}
\hline Fase & Tarefa-Chave & $\begin{array}{c}\text { Comportamentos } \\
\text { Positivos do } \\
\text { Cuidadores } \\
\text { Informais }\end{array}$ & $\begin{array}{l}\text { Comportamentos } \\
\text { Problemáticos dos } \\
\text { Cuidadores } \\
\text { Informais }\end{array}$ \\
\hline $\begin{array}{l}\text { Inicio da } \\
\text { doença }\end{array}$ & $\begin{array}{l}\text { Reconhecimento dos } \\
\text { limites impostos } \\
\text { pela doença. } \\
\text { Vontade de aceitar } \\
\text { os cuidados } \\
\end{array}$ & $\begin{array}{l}\text { Discussão aberta. } \\
\text { Ofertas de apoio. }\end{array}$ & $\begin{array}{l}\text { Negação das } \\
\text { alterações. } \\
\text { Culpabilização do } \\
\text { doente. }\end{array}$ \\
\hline $\begin{array}{l}\text { Impacto da } \\
\text { doença }\end{array}$ & $\begin{array}{l}\text { Aceitação do } \\
\text { diagnóstico, } \\
\text { adaptação às } \\
\text { capacidades físicas, } \\
\text { planeamento do } \\
\text { tratamento. }\end{array}$ & $\begin{array}{l}\text { Discussão aberta. } \\
\text { Partilha de tarefas. } \\
\text { Apoio na restante } \\
\text { autonomia. }\end{array}$ & $\begin{array}{l}\text { Desestabilização do } \\
\text { equilíbrio e relações } \\
\text { existentes na família. } \\
\text { Comportamentos } \\
\text { abusivos. }\end{array}$ \\
\hline $\begin{array}{c}\text { Início da } \\
\text { reabilitação }\end{array}$ & $\begin{array}{l}\text { Reorganização das } \\
\text { responsabilidades, } \\
\text { lidar com } \\
\text { implicações } \\
\text { financeiras e outras. }\end{array}$ & $\begin{array}{l}\text { Partilha de } \\
\text { responsabilidades. } \\
\text { Planeamento } \\
\text { realista do futuro. }\end{array}$ & $\begin{array}{l}\text { Recusa dos cuidados } \\
\text { prestados. }\end{array}$ \\
\hline $\begin{array}{c}\text { Reabilitação } \\
\text { precoce }\end{array}$ & $\begin{array}{l}\text { Reintegração na } \\
\text { família e na } \\
\text { sociedade. }\end{array}$ & $\begin{array}{l}\text { Flexibilização das } \\
\text { expetativas. } \\
\text { Novos papéis no } \\
\text { interior da família. }\end{array}$ & $\begin{array}{l}\text { Reações tardias, em } \\
\text { particular quando a } \\
\text { doença é súbita ou } \\
\text { traumática. } \\
\text { Desejo de ganhos } \\
\text { secundários. }\end{array}$ \\
\hline $\begin{array}{l}\text { Adaptação à } \\
\text { permanênci } \\
\text { a da fase } \\
\text { final }\end{array}$ & $\begin{array}{l}\text { Redefinição da } \\
\text { autoestima e } \\
\text { significado. }\end{array}$ & $\begin{array}{l}\text { Aceitação dos } \\
\text { doentes como eles } \\
\text { são. }\end{array}$ & $\begin{array}{l}\text { Má vontade em } \\
\text { aceitar ou adaptar-se } \\
\text { às exigências da } \\
\text { situação. }\end{array}$ \\
\hline
\end{tabular}

Este quadro apresenta uma proposta de tipificação dos possíveis comportamentos dos Cuidadores informais. Comportamentos esses que afetam positiva ou negativamente o doente, dependendo da reação dos Cuidadores à doença e à dependência deste.

Os cuidadores que têm uma visão otimista dos pequenos progressos tendo consciência da realidade, que não dramatizam, que procuram obter informações, "são aqueles que vão dar um maior incentivo aos membros doentes e obter uma melhor qualidade de vida para toda a família" (Barros, 2003, citado por Monteiro, 2010, p. 43). 
A Rede Nacional de Cuidados Continuados Integrados (RNCCI) promove a participação dos Cuidadores Informais através da prestação de cuidados com a envolvência da equipa multidisciplinar, composta por Assistente Social, Enfermeiros, Médicos, Psicólogos, Fisioterapeutas, Nutricionistas, entre outros. O Cuidador Informal tem conhecimento do plano de cuidados e objetivos a atingir e poderá participar na intervenção, desde que essa seja positiva e o doente a aceite (Unidade de Missão para os Cuidados Continuados, 2010, p. 30).

Em 2008 surgiu o Projeto "O Cuidador Informal em Parceria nos Cuidados" integrado no Programa dos Padrões de Qualidade dos Cuidados de Enfermagem e implementado na Unidade de Convalescença do Hospital do Arcebispo João Crisóstomo, onde se verificou que $49 \%$ dos $65 \%$ dos Cuidadores dos doentes dependentes entrevistados foram integrados nos cuidados a realizar (Reis, Oliveira \& Silvestre, 2011, p. 58).

Monteiro (2010, p. 51) acredita que [...] "a família tem um papel fundamental na recuperação do doente, e que a sua participação nos cuidados significa efectivamente uma melhoria no bem-estar do seu doente e uma mais-valia para que haja humanização de cuidados de saúde".

"O papel do cuidador tem sido reconhecido como central numa abordagem multidisciplinar, na qual interagem diferentes profissionais". Verifica-se que o cuidador exerce influência na evolução das doenças principalmente na frequência e gravidade dos problemas comportamentais e na deterioração das capacidades funcionais (Melo, 2005, citado por Pereira, 2011, p. 64).

Barrer (1988, citado por Silva, 2004, p. 65) classifica o suporte familiar e o envolvimento desta cruzando duas variáveis (Quadro II):

$\checkmark \mathrm{O}$ suporte familiar, que diz respeito à tomada de decisão do Cuidador Informal relativamente ao doente e a indicações dos profissionais;

$\checkmark \mathrm{O}$ envolvimento familiar que corresponde à proximidade física $\mathrm{e}$ emocional com o doente e com a equipa prestadora de cuidados.

\section{Quadro II}

Modelo de envolvimento e suporte familiar de Barrer

\begin{tabular}{ccc}
\hline & Com suporte & Sem suporte \\
\hline Envolvida & Envolvida / Com suporte & Envolvida / Sem suporte \\
\hline Não envolvida & Não envolvida / Com suporte & Não envolvida / Sem suporte \\
\hline
\end{tabular}


Barrer (1988, citado por Silva, 2004, p. 65) descreve os quatro tipos de família:

$\checkmark$ Uma família envolvida e com suporte é aquela que se interessa com o tratamento prestado ao doente e segue as recomendações dos profissionais. Este tipo de família é bastante protetora contribuindo para que o doente se torne dependente.

$\checkmark$ Os familiares que são envolvidos mas que não prestam suporte ao doente dizem respeito àqueles que confiam pouco nos profissionais, que não têm noção da realidade nem das capacidades do doente e são pessimistas.

$\checkmark$ A família não envolvida mas que presta suporte, é a família que não toma decisões e mostra dúvidas na intervenção dos profissionais. "Apesar de encorajarem o doente a ser independente, seguem com pouca frequência as recomendações da equipa".

$\checkmark$ Por último a família não envolvida e sem suporte, é aquela que não quer responsabilidades, não seguem as recomendações dos profissionais e até se distanciam do doente.

Este modelo permite perceber os diversos tipos de papéis desempenhados pelos Cuidadores Informais durante o internamento do doente (Silva, 2004, p. 66).

O reconhecimento da importância da família no acompanhamento do processo do doente, leva a que este seja tido como "sistema parceiro das intervenções [...] É frequente os familiares serem envolvidos diretamente na gestão da medicação e na monitorização dos sintomas e dos comportamentos do doente, tendo-os como parceiros da equipa de saúde" (Guadalupe, 2012, p. 211).

A integração dos Cuidadores Informais no processo de acolhimento e reabilitação dos doentes tem como intuito a satisfação e o bem-estar destes, originando neles um sentimento de apoio e cooperação, como também a preparação dos Cuidadores Informais para uma melhor prestação de cuidados, no sentido de estes se sentirem integrados na dinâmica da instituição e no processo de acolhimento e reabilitação do seu doente.

\section{METODOLOGIA}

Desenvolveu-se um estudo empírico tendo como objetivo geral perceber de que modo a presença dos Cuidadores Informais afeta positiva ou 
negativamente a reabilitação dos doentes. Consideraram-se como objetivos específicos do presente estudo:

- Aferir qual a relação de proximidade entre os Cuidadores Informais e os doentes;

- Perceber o grau de satisfação dos doentes face às visitas dos Cuidadores Informais;

- Conhecer o grau de satisfação dos doentes face à participação dos Cuidadores Informais nas suas atividades;

- Apurar se os Cuidadores Informais acompanham os doentes na realização das suas atividades.

O presente estudo permitiu através do cruzamento de variáveis, formular e testar hipóteses, sendo a hipótese geral: A presença dos Cuidadores Informais influencia positivamente a reabilitação dos doentes.

As hipóteses específicas foram formuladas de acordo com a observação realizada na Unidade de Cuidados Continuados da Santa Casa da Misericórdia de Mangualde, são elas:

H1: A relação de proximidade dos Cuidadores Informais com os doentes tem influência no número de visitas a realizar aos doentes;

H2: Os Cuidadores Informais que participam nas atividades são aqueles que possuem maior relação de proximidade com os doentes;

H3: Quando os Cuidadores Informais participam nas atividades existe um maior grau de satisfação dos doentes.

A opção metodológica que orientou este estudo foi o inquérito por questionário aplicado através do contato direto aos Cuidadores Informais. Foi elaborado após a revisão da literatura e da observação direta aos Cuidadores Informais com os doentes na Unidade de Cuidados Continuados da Santa Casa da Misericórdia de Mangualde. É um estudo descritivo, correlacional e quantitativo, pois procura descrever as simples variáveis, relacioná-las e quantifica-las (Dias, 2009, 2010).

A população do presente estudo corresponde aos Cuidadores Informais da Unidade de Cuidados Continuados da Santa Casa da Misericórdia de Mangualde coincidente com a população-alvo e com a amostra, uma vez que os questionários foram aplicados a toda a população.

Esta população foi escolhida por conveniência, dado o facto do tema ser "Influência do Cuidador Informa na Reabilitação do doente, no Contexto dos Cuidados Continuados".

A população era de 38 Cuidadores Informais, população máxima da Unidade de Cuidados Continuados da Santa Casa da Misericórdia de Mangualde, contudo 4 doentes não têm Cuidador Informal e 1 Cuidador Informal não foi encontrado pessoalmente, nem por contato telefónico, o 
que impossibilitou a realização dos questionários a todos os Cuidadores Informais. Estas limitações diminuem o total de questionários aplicados para 33 questionários.

O questionário divide-se em 4 partes, correspondendo a primeira parte à caraterização sociodemográfica do Cuidador Informal; a segunda está direcionada para as visitas do Cuidador Informal ao doente; a terceira diz respeito à importância do Cuidador Informal e por último a quarta parte que corresponde à participação do Cuidador Informal nas atividades realizadas pelo doente.

\section{RESULTADOS}

Nesta fase são apresentados as características dos Cuidadores Informais, bem como as relações de parentesco destes com os doentes, a relação de proximidade entre eles, a participação dos Cuidadores Informais nas atividades realizadas pelos doentes, o grau de satisfação destes com as visitas dos Cuidadores Informais, e por fim é realizada a análise inferencial para verificação das hipóteses formuladas.

\subsection{Caraterização e Relações de Parentesco dos Cuidadores Informais}

Segue-se no Quadro III a caraterização sociodemográfica da população inquirida:

\section{Quadro III}

\begin{tabular}{|c|c|c|c|}
\hline \multirow{3}{*}{ Género } & & $\mathbf{N}$ & $\%$ \\
\hline & Masculino & 12 & 36,4 \\
\hline & Feminino & 21 & 63,6 \\
\hline \multirow{4}{*}{ Idade } & $20-40$ & 5 & 15,2 \\
\hline & $41-60$ & 19 & 57,6 \\
\hline & $61-80$ & 7 & 21,2 \\
\hline & $>80$ & 2 & 6,1 \\
\hline \multirow{4}{*}{ Estado Civil } & Solteiro & 1 & 3,0 \\
\hline & Casado/União de Fato & 25 & 75,8 \\
\hline & Divorciado/Separado & 5 & 15,2 \\
\hline & Viúvo & 2 & 6,1 \\
\hline \multirow{7}{*}{ Habilitações } & Sem escolaridade & 0 & 0 \\
\hline & Só sabe assinar & 1 & 3,0 \\
\hline & Ensino Básico $-1^{\circ} \mathrm{Ciclo}$ & 10 & 30,3 \\
\hline & Ensino Básico $-2^{\circ}$ Ciclo & 7 & $\frac{21,2}{21,2}$ \\
\hline & Ensino Básico $-3^{\circ}$ Ciclo & 7 & 21,2 \\
\hline & Ensino Secundário & 6 & 18,2 \\
\hline & Ensino Superior & 2 & 6,1 \\
\hline
\end{tabular}


Como podemos observar no Quadro III os entrevistados eram maioritariamente do sexo feminino $(n=21 ; 63,6 \%)$, com idades maioritariamente compreendidas entre os 41 e os 60 anos $(n=19 ; 57,6 \%)$. Relativamente ao estado civil a grande maioria $(n=25 ; 75,8 \%)$ dos Cuidadores Informais são casados ou vivem em união de facto, tendo maioritariamente ( $\mathrm{n}=10 ; 30,3 \%)$ o $1^{\circ}$ Ciclo do Ensino Básico $-4^{\circ}$ ano.

O quadro seguinte refere-se à relação de parentesco existente entre os Cuidadores Informais e os doentes:

\section{Quadro IV}

Relação de Parentesco entre os Cuidadores Informais e os Doentes

\begin{tabular}{llcc}
\hline & & $\mathbf{N}$ & $\mathbf{\%}$ \\
\hline \multirow{4}{*}{$\begin{array}{l}\text { Relação de } \\
\text { Parentesco }\end{array}$} & Marido/Esposa & 9 & 27,3 \\
\cline { 2 - 4 } & Filho (a) & 15 & 45,5 \\
\cline { 2 - 4 } & Nora/Genro & 2 & 6,1 \\
\cline { 2 - 4 } & Neto (a) & 1 & 3,0 \\
\cline { 2 - 4 } & Não é familiar & 1 & 3,0 \\
\cline { 2 - 4 } & Outro familiar & 5 & 15,2 \\
\hline & Total & $\mathbf{3 3}$ & $\mathbf{1 0 0}$ \\
\hline
\end{tabular}

A relação de parentesco entre os Cuidadores Informais e os doentes é principalmente relação de descendência (filhos) $(n=15 ; 45,5 \%)$ e de marido/esposa $(\mathrm{n}=9 ; 27,3 \%)$. Apenas um Cuidador Informal não é familiar.

\subsection{Relação de Proximidade e Participação dos Cuidadores Informais}

O Quadro V reflete que $84,8 \%(\mathrm{n}=28)$ dos Cuidadores Informais dizem estar muito próximos dos doentes, $9,1 \%(\mathrm{n}=3)$ dizem ser próximos e $6,1 \%$ $(\mathrm{n}=2)$ dizem ser pouco próximos.

\section{Quadro V}

Relação de Proximidade dos Cuidadores Informais com os Doentes

\begin{tabular}{ccc}
\hline $\begin{array}{c}\text { Relação de Proximidade dos } \\
\text { Cuidadores Informais com os doentes }\end{array}$ & $\mathbf{N}$ & $\boldsymbol{\%}$ \\
\hline 1 - Pouco próximos & 2 & 6,1 \\
\hline 2 - Próximos & 3 & 9,1 \\
\hline 3 - Muito próximos & 28 & 84,8 \\
\hline Total & 33 & 100 \\
\hline
\end{tabular}


O Quadro VI corresponde ao grau de satisfação dos doentes face às visitas dos Cuidadores Informais, evidenciando que os doentes ficam maioritariamente muito felizes $(n=16 ; 48,5 \%)$ com a visita dos Cuidadores Informais, verificando-se $4(\mathrm{n}=12,1 \%)$ doentes que ficam indiferentes e 4 $(\mathrm{n}=12,1 \%)$ que ficam contentes.

\section{Quadro VI}

Grau de Satisfação dos Doentes face às Visitas dos Cuidadores Informais

\begin{tabular}{ccc}
\hline $\begin{array}{c}\text { Grau de Satisfação dos Doentes face às } \\
\text { Visitas dos Cuidadores Informais }\end{array}$ & N & \% \\
\hline 1 - Indiferença & 4 & 12,1 \\
\hline 2 - Contente & 4 & 12,1 \\
\hline 3 - Feliz & 9 & 27,3 \\
\hline 4- Muito Feliz & 16 & 48,5 \\
\hline Total & 33 & 100 \\
\hline
\end{tabular}

Segue-se o Quadro VII, que evidencia que 63,6\% (n=21) dos Cuidadores Informais manifesta participar nas atividades realizadas com os doentes. Estas atividades correspondem à alimentação, medicação, higiene, fisioterapia e atividades de animação.

\section{Quadro VII}

Participação dos Cuidadores Informais nas Atividades Realizadas com os Doentes

\begin{tabular}{ccc}
\hline $\begin{array}{c}\text { Participação dos Cuidadores } \\
\text { Informais nas atividades realizadas } \\
\text { com os doentes }\end{array}$ & $\mathbf{N}$ & $\mathbf{\%}$ \\
\hline Sim & 21 & 63,6 \\
\hline Não & 12 & 36,4 \\
\hline Total & 33 & 100 \\
\hline
\end{tabular}

Por fim, o Quadro VIII, que demonstra o grau de satisfação dos doentes quando o Cuidador Informal participa nas suas atividades, aferindo-se que os doentes ficam maioritariamente muito felizes $(\mathrm{n}=11 ; 33,3 \%)$ quando os Cuidadores Informais participam nas suas atividades, comparativamente a $4(12,1 \%)$ doentes que ficam indiferentes. 


\section{Quadro VIII}

Grau de Satisfação dos Doentes quando o Cuidador Informal participa nas suas Atividades

\begin{tabular}{ccc}
\hline $\begin{array}{c}\text { Grau de Satisfação dos Doentes } \\
\text { quando o Cuidador Informal participa } \\
\text { nas suas Atividades }\end{array}$ & $\mathbf{N}$ & $\mathbf{\%}$ \\
\hline 1 - Indiferença & 4 & 12,1 \\
\hline 2 - Contente & 10 & 30,3 \\
\hline 3 - Feliz & 8 & 24,2 \\
\hline 4 - Muito Feliz & 11 & 33,3 \\
\hline Total & 33 & 100 \\
\hline
\end{tabular}

\subsection{Análise inferencial}

Este ponto incidiu na verificação das hipóteses formuladas. Inicialmente teve de se testar a normalidade dos dados, com os teste de normalidade de Kolmogorov-Smirnov-Lilliefors e de Shapiro-Wilk. Não se verificou a normalidade da distribuição dos valores das variáveis em estudo, pelo que serão utilizados os testes não paramétricos para amostras independentes para verificar as hipóteses formuladas, ou seja, o Coeficiente de Correlação de Spearman para testar a hipótese 1 e o teste Mann-Whitney U para testar as restantes hipóteses.

H1: A relação de proximidade dos Cuidadores Informais com os doentes tem influência no número de visitas a realizar aos doentes

\section{Quadro IX}

Relação de associação entre a visita aos doentes e a relação de proximidade

\begin{tabular}{clrr}
\hline & Correlation Coefficient & $\begin{array}{c}\text { Visita aos } \\
\text { doentes }\end{array}$ & $\begin{array}{c}\text { Relação de } \\
\text { proximidade }\end{array}$ \\
\hline Visita aos & Sig. (2-tailed) & &, 276 \\
doentes & $\mathrm{N}$ & 33 &, 120 \\
& Correlation Coefficient &, 276 & 33 \\
\hline \multirow{2}{*}{ Relação de } & Sig. (2-tailed) &, 120 & 1,000 \\
proximidade & $\mathrm{N}$ & 33 & 33 \\
\hline
\end{tabular}

Os resultados permitem verificar que a hipótese 1 não se confirma ( $\mathrm{P}=$ $0,120)$.

H2: Os Cuidadores Informais que participam nas atividades são aqueles que possuem maior relação de proximidade com os doentes. 


\section{Quadro X}

Relação da participação dos Cuidadores Informais nas atividades com a relação de proximidade

\begin{tabular}{ccccc}
\hline & $\begin{array}{c}\text { Participação nas } \\
\text { atividades }\end{array}$ & N & Mean Rank & P \\
\hline \multirow{2}{*}{$\begin{array}{c}\text { Relação de } \\
\text { proximidade }\end{array}$} & Sim & 21 & 18,02 & \\
\cline { 2 - 5 } & Não & 12 & 15,21 & \\
\cline { 2 - 5 } & Total & 33 & &, 197 \\
\hline
\end{tabular}

O teste permite apurar que a hipótese 2 não se confirma $(\mathrm{P}=0,197)$.

H3: Quando os Cuidadores Informais participam nas atividades existe um maior grau de satisfação dos doentes.

\section{Quadro XI}

Relação entre a participação dos Cuidadores Informais nas atividades e a satisfação dos doentes

\begin{tabular}{ccccc}
\hline & $\begin{array}{c}\text { Participação nas } \\
\text { atividades }\end{array}$ & N & Mean Rank & P \\
\hline \multirow{2}{*}{$\begin{array}{c}\text { Satisfação dos } \\
\text { doentes }\end{array}$} & Sim & 21 & 18,48 & \\
\cline { 2 - 5 } & Não & 12 & 14,42 & \\
\cline { 2 - 5 } & Total & 33 & &, 226 \\
\hline
\end{tabular}

Aferiu-se que a última hipótese irá ser refutada $(\mathrm{P}=0,226)$.

\section{DISCUSSÃO DOS RESULTADOS}

Neste ponto far-se-á a discussão dos resultados expostos nos pontos anteriores, fazendo a sua comparação com a literatura.

A população estudada é maioritariamente do sexo feminino, que segue o padrão descrito na literatura, como profere Jullamate, et al. (2006, citado por Azeredo, 2011, p. 93) "Embora não haja um padrão de cuidador principal sabe-se que há um predomínio do sexo feminino, de pessoas a cohabitarem ou geograficamente próximas, e de familiares, nomeadamente conjugues ou filhas/noras.".

Relativamente à relação de parentesco dos Cuidadores Informais com os doentes, a maioria são filhos (as) e marido/esposa destes. A opção "outro familiar" apresenta como sendo Cuidadores Informais, a sobrinha, o tio, o irmão e o cunhado do doente. Este resultado enquadra-se na 
argumentação de Azeredo (2011, pp. 90-102) pois este afirma que apesar das mudanças ao longo do tempo no seio familiar, o apoio intergeracional ainda se verifica, assumindo os filhos os cuidados a prestar aos seus pais. Os Cuidadores Informais tendem a ser "[...] pessoas a co-habitarem ou geograficamente próximas, e de familiares, nomeadamente conjugues ou filhas/noras" (Azeredo, 2011, p. 93).

A relação de proximidade entre o Cuidador Informal e o doente é maioritariamente muito próxima, facto que pode estar interligado com a relação de parentesco ser maioritariamente filhos (as) e marido/esposa, que implica serem pessoas próximas do doente. Imaginário (2004, pp. 70-71) diz que é no seio da família que as necessidades básicas são satisfeitas, bem como o apoio emocional, afetos e emoções. Castro (2008, p. 47) completa dizendo que cuidar de uma pessoa idosa implica solidariedade, responsabilidade e dever.

No que diz respeito à atitude dos doentes face às visitas dos Cuidadores Informais, esta é bastante positiva, pois do ponto de vista destes a maioria dos doentes fica muito feliz com a sua visita, sendo que quatro Cuidadores Informais assinalaram a opção indiferente para descrever a atitude dos doentes à sua visita. Esta resposta pode dever-se ao facto de alguns doentes estarem acamados, totalmente dependentes, sem verbalizar ou ter algum tipo de reação, o que impossibilita a manifestação ou o desenvolvimento dos laços afetivos que ajudam no processo de reabilitação.

Outro aspeto a considerar é o fato de alguns doentes quando dependentes, mas cognitivamente em bom estado clínico, ao sentirem a preocupação dos seus Cuidadores Informais, ao perceberem que estes têm que deixar de fazer as suas atividades diárias para se deslocar à Unidade de Cuidados Continuados várias vezes para estar com eles, surgem sentimentos de "ser um peso" para o seu familiar/cuidador, significando que a opção indiferente também pode dever-se a este fator.

Relativamente à participação dos Cuidadores Informais nas atividades realizadas com os doentes, grande parte assinalaram a resposta afirmativa. Monteiro (2010, p. 51) acredita "que a família tem um papel fundamental na recuperação do doente, e que a sua participação nos cuidados significa efetivamente uma melhoria no bem-estar do seu doente e uma mais-valia para que haja humanização de cuidados de saúde".

A razão pela qual os Cuidadores Informais não participam nas atividades deve-se ao facto dos doentes não estarem, na altura, a realizar atividades. Isto pode acontecer devido aos Cuidadores Informais visitarem os doentes no período final da tarde, depois do trabalho, o que condiciona a sua presença/participação em algumas atividades, como a fisioterapia e a 
animação. Contudo os cuidados de higiene e posicionamentos são realizados regularmente, bem como a alimentação, neste caso o jantar é fornecido na Unidade de Cuidados Continuados da Santa Casa da Misericórdia de Mangualde às $18 \mathrm{~h}$ e o Cuidador Informal como tem horário alargado até às $19 \mathrm{~h} 30$, pode estar presente e até ajudar na reabilitação da autonomia do doente, como comer por mão própria, o mesmo acontece com o almoço e o lanche. No período da tarde, está sempre presente uma fisioterapeuta a trabalhar com os doentes, no entanto, estes dependendo das suas necessidades de fisioterapia, têm dias estipulados para a sua realização, o que pode acontecer não coincidir com a visita do Cuidador Informal. As atividades de animação são realizadas aleatoriamente, sem dias específicos, porém há doentes que não podem participar devido ao seu estado clínico. "Deve ser convicção de uma equipa de reabilitação que o envolvimento da família no processo de reabilitação favoreça a integração do doente e promova a sua qualidade de vida" (Warlow C. et al., 1987 \& Evans RL. et al., 1988, citado por Silva, 2010, p. 21).

A opção "outra razão" para o Cuidador Informal não participar nas atividades realizadas com o doente, foi assinalada como o facto do Cuidador Informal nem sempre poder estar presente em determinadas situações. Este acontecimento pode dever-se a intervenções mais específicas dos profissionais, em que não é pertinente a presença do Cuidador Informal.

$\mathrm{O}$ estado dos doentes quando os Cuidadores Informais participam nas suas atividades é considerado por estes, na sua maioria, muito feliz, que indica que os doentes gostam e sentem-se bem com a presença do Cuidador Informal na realização das suas atividades. Cunha (2003, p. 62 citado por Monteiro, 2010, p. 51) refere que a participação da família nos cuidados permite a esta estar informada sobre intervenções a realizar e, consequentemente diminuição da ansiedade do prestador de cuidados, suscitando no doente um sentimento de ambiente natural e familiar, contribuindo para o seu bem-estar.

A segunda parte da análise incidiu na verificação das hipóteses formuladas, em que se constatou na hipótese 1, que as variáveis visita ao doente e relação de proximidade não dependem diretamente uma da outra $(\mathrm{P}=0,120)$, porém verifica-se uma associação positiva (Coeficiente de Correlação $=0,276$ ) entre elas.

A verificação da hipótese 2 permitiu apurar que não existem diferenças significativas $(\mathrm{P}=0,197)$, o que indica que, a relação de proximidade parece não ter influência positiva ou negativa, na participação dos 
Cuidadores Informais nas atividades realizadas com os doentes, porém verificam-se algumas diferenças, uma vez que os Cuidadores Informais que participam nas atividades são os que mantêm maior relação de proximidade $(\mathrm{M}=18,02)$, comparativamente aos que não participam nas atividades a relação de proximidade é menor $(\mathrm{M}=15,21)$.

$\mathrm{Na}$ verificação da hipótese 3 aferiu-se que também não existem diferenças significativas $(\mathrm{P}=0,226)$, ou seja, a participação dos Cuidadores Informais nas atividades realizadas com os doentes parece não influenciar positiva ou negativamente, o grau de satisfação dos doentes quando os Cuidadores Informais participam nessas atividades, todavia existem algumas diferenças, uma vez que os Cuidadores Informais que dizem participar nas atividades realizadas com os doentes são aqueles que provocam nos doentes maior grau de satisfação $(M=18,48)$, relativamente aos Cuidadores Informais que dizem não participar nas atividades realizadas com os doentes, aqueles que provocam no doente um menor grau de satisfação $(M=14,42)$.

Pode-se concluir, através do nosso estudo e de acordo com a literatura, que o Cuidador Informal influencia positivamente a reabilitação do doente, conseguindo concretizar o objetivo geral proposto, ou seja, perceber de que modo a presença dos Cuidadores Informais afeta positiva ou negativamente a reabilitação dos doentes.

Os Cuidadores Informais ao fazerem parte das intervenções a realizar aos doentes devem-se reger pelas orientações dos profissionais para que a intervenção seja bem-sucedida. Mas a par da positividade da ajuda da equipa multidisciplinar ao Cuidador Informal, lidar com o fato de ter um familiar ou pessoa próxima que necessita de cuidados difíceis e exigentes provoca no cuidador responsabilidades acrescidas, tensão e cansaço, sendo o seu comportamento observado pelos profissionais e aconselhado, caso assim se justifique. Assim o processo de reabilitação acompanhado pelos Cuidadores Informais requer por parte destes capacidade emocional para lidar com a dependência, com a recuperação lenta e com as recaídas, acrescentando em muitos casos o fato dos Cuidadores Informais terem eles também problemas de saúde, ou idade avançada, dificultando a ajuda da sua participação na reabilitação dos doentes na Unidade de Cuidados Continuados e os cuidados no domicilio.

Como está descrito na literatura, "quem cuida deve cuidar-se para melhor cuidar", acrescentando que deve também ser cuidado. Ou seja, temos de cuidar de quem cuida, equacionando a família no seu duplo papel de apoiante e apoiada, pois, quando temos uma família nesta situação, é fundamental concentrarmos também a nossa atenção em quem apoia a família a apoiar" (Guadalupe, 2012, p. 212). 
Os profissionais também são confrontados com a falta de escolaridade dos Cuidadores Informais, com a idade avançada, com a dificuldade sentida por estes em cuidados que requerem mais esforço físico, tendo os profissionais que se adaptar às características dos Cuidadores Informais para os ensinar e incentivar na reabilitação dos doente.

O processo de reabilitação é realizado por profissionais de diversas áreas, para que a recuperação abrange várias áreas da condição física e social do doente e Cuidadores Informais. "[...] a reabilitação deve ser feita por uma equipa interdisciplinar de profissionais de saúde de diversas áreas, sempre que possível com o envolvimento de familiares e amigos" (Stroke Unit Trialists' Collaboration, 2007, citado por Silva, 2010, p. 14).

\section{CONCLUSÃO}

A presente investigação foi fundamental para a compreensão da própria temática e valorização dos Cuidadores Informais como elementos intervenientes dos cuidados a prestar aos doentes.

A reabilitação dos doentes implica segundo DeLisa, Currie \& Martin (2002, p. 3) "ajudar uma pessoa a atingir seu melhor potencial físico, psicológico, social, vocacional e educacional, compatível com seu deficit fisiológico ou anatômico, limitações ambientais, desejos e planos de vida". Esta tem como intervenientes uma Equipa Multidisciplinar, mas também como parceiros familiares e amigos do doente (Stroke Unit Trialists' Collaboration, 2007, citado por Silva, 2010, p. 14).

$\mathrm{Se}$ os Cuidadores Informais forem incluídos no processo de acolhimento e reabilitação dos doentes, estes estarão informados das intervenções a realizar e como as realizar, ajudando os profissionais e criando nos doentes sentimentos de bem-estar e de ambiente familiar.

A experiência vivida com a população-alvo, permitiu-nos perceber que os Cuidadores Informais são muito valorizados e englobados no processo de reabilitação dos doentes através de reuniões diárias, identificação de expetativas e inserção destes nas atividades desenvolvidas pelos doentes.

A investigação empírica permitiu apurar o grau de satisfação dos doentes, que é maioritariamente muito feliz quando os Cuidadores Informais os vão visitar e quando estes participam nas atividades realizadas com os doentes. Pode-se deduzir que esta satisfação significa que os doentes gostam de ter o Cuidador Informal por perto e de mostrar as suas capacidades.

Para concluir, é necessário que os profissionais estejam atentos aos comportamentos dos Cuidadores Informais e inseri-los no processo de 
reabilitação dos doentes, para que eles também se sintam enquadrados e úteis na sua reabilitação.

O presente estudo permitiu encontrar resultados que vão ao encontro da literatura e atingir os objetivos propostos. Podendo-se afirmar que os Cuidadores Informais influenciam positivamente a reabilitação dos doentes.

\section{REFERÊNCIAS BIBLIOGRÁFICAS}

Azeredo, Z. (2011). O Idoso como um todo. Viseu: Psicosoma.

Castro, S. C. P. (2008). Como aprende o cuidador principal do doente oncológico em fase terminal a cuidar no domicílio. Dissertação de Mestrado em Ciências de Enfermagem, Instituto de Ciências Biomédicas Abel Salazar - Universidade do Porto, Portugal. Acedido em 10 de Dezembro de 2012, em http://repositorioaberto.up.pt/bitstream/ 10216/19379/2/TeseSusana.pdf.

Decreto-Lei no 101/2006 de 06 de Junho. Diário da República n ${ }^{\circ} 109$ - I Série. Acedido em 17 de Outubro de 2012, em http://dre.pt/pdf1sdip/ 2006/06/109A00/38563865.pdf.

DeLisa, J. A., Currie, D. M. \& Martin, G. M. (2002). Medicina de reabilitação: Passado, presente e futuro. In DeLisa, J. A. \& Gans, B. M., Tratado de medicina de reabilitação: Princípios e práticas, $\left(3^{\mathrm{a}}\right.$ ed). (Vol. I). (pp. 3-11). Brasil: Editora Manole Ltda.

Dias, M. O. (2010). Planos de investigação: Avançando passo a passo. Santa Maria da Feira: Rainho \& Neves, Lda.

Dias, M.O. (2009). Vocabulário do desenho de investigação: A lógica do processo em ciências sociais. Viseu: Psicossoma.

Guadalupe, S. (2012). A intervenção do serviço social na saúde com famílias e em redes de suporte social. In Carvalho, M. I., Serviço social na saúde (pp. 183-217). Lisboa: Pactor - Edições de Ciências Sociais e Política Contemporânea.

Guerreiro, I. (2009). Desafios de um modelo integrado. (2 ${ }^{\mathrm{a}}$ ed). Lisboa: Gráfica Offset Mais - Artes Gráficas S. A.

Imaginário, C. (2004). O Idoso dependente em contexto familiar: Uma análise de visão da família e do cuidador principal. Coimbra: Edição Formasau - Formação e Saúde, Lda.

José, J.S., Wall, K. \& Correia, S.V. (2002). Trabalhar e cuidar de um idoso dependente: Problemas e soluções. Pesquisa qualitativa exploratória desenvolvida no âmbito de um projeto de investigação europeu - Instituto de Ciências Sociais - Universidade de Lisboa, Portugal. Acedido em 10 de Dezembro de 2012, em 
http://www.ics.ul.pt/ publicacoes/workingpapers/wp2002/WP22002.pdf.

Monteiro, M. C. D. (2010). Vivência dos cuidadores familiares em internamento hospitalar - $O$ início da dependência. Dissertação de Mestrado em Ciências de Enfermagem, Instituto de Ciências Biomédicas Abel Salazar - Universidade do Porto, Portugal. Acedido em 10 de Dezembro de 2012, em http://repositorioaberto.up.pt/bitstream/10216/26357/2/Maria\%20Clara\%20Duarte\% 20Monteiro.pdf.

Pereira, M. F. C. (2011). Cuidadores informais de doentes de alzheimer: sobrecarga física, emocional e social e psicopatologia. Dissertação de Mestrado em Ciências de Enfermagem, Instituto de Ciências Biomédicas Abel Salazar - Universidade do Porto, Portugal. Acedido em 10 de Dezembro de 2012, em http://repositorioaberto. up.pt/bitstream/10216/7152/2/Cuidadores\%20Informais\%20de\%20D oentes\%20de\%20Alzheimer\%20Sobrecarga\%20Fis.pdf.

Reis, M. L., Oliveira, C. \& Silvestre, T. (2011). Programa dos padrões de qualidade dos cuidados de enfermagem - $\mathrm{O}$ cuidador informal em parceria nos cuidados. In Governação clínica e estratégias profissionais. Revista Ordem dos Enfermeiros. N ${ }^{\circ}$ 38, pp. 58-59. Lisboa.

Silva, C. M. M. O. V. (2004). Família, doença mental e reabilitação psicossocial. Dissertação de Mestrado em Psicopatologia e Psicologia Clinica, Instituto Superior de Psicologia Aplicada, Portugal. Acedido em 10 de Dezembro de 2012, em http://repositorio.ispa.pt/ handle/10400.12/927.

Silva, E. J. A. (2010). Reabilitação após o AVC. Dissertação de Mestrado Integrado em Medicina, Faculdade de Medicina da Universidade do Porto, Portugal. Acedido em 10 de Dezembro de 2012, em http://repositorio-aberto.up.pt/bitstream/10216/52151/2/Reabilitao\% 20aps $\% 20 \mathrm{o} \% 20$ AVC.pdf.

Unidade, M. P. C. C. (org) (2010). Estratégia para o desenvolvimento do programa nacional de cuidados paliativos- Rede nacional de cuidados continuados integrados 2011-2013. Acedido em 10 de Dezembro de 2012, em http://www.rncci.min-saude.pt/SiteCollection Documents/cuidadospaliativos_1-1-2011.pdf. 